\title{
Identification and Characterization of Colletotrichum Species Associated with Anthracnose Disease of Camellia oleifera in China
}

\author{
Yixun Wang, ${ }^{1,2}$ Jing-Yuan Chen, ${ }^{2}$ Xiaowen $\mathrm{Xu}^{2}{ }^{2}$ Junyong Cheng, ${ }^{2}$ Lu Zheng, ${ }^{1}$ Junbin Huang, ${ }^{1, \dagger}$ and De-Wei Li ${ }^{3}$ \\ ${ }^{1}$ Key Laboratory of Plant Pathology of Hubei Province, Huazhong Agricultural University, Wuhan, Hubei 430070, China \\ ${ }^{2}$ Institute of Forest Protection, Hubei Academy of Forestry, Wuhan, Hubei 430075, China \\ ${ }^{3}$ Connecticut Agricultural Experiment Station Valley Laboratory, Windsor, CT 06095, U.S.A.
}

\begin{abstract}
Tea-oil tree (Camellia oleifera Abel) is an important edible oil woody plant with a planting area over 3,800,000 hectares in southern China. Anthracnose is a serious disease of tea-oil tree in southern China, causing severe economic losses and posing a huge threat to the Ca. oleifera industry. Based on recent developments in the classification of Colletotrichum species, the objective of this study was to identify Colletotrichum species associated with tea-oil tree and examine their pathogenicity on leaves and fruits of Ca. oleifera. In total, 232 isolates were obtained from $\mathrm{Ca}$. oleifera leaves and fruits with anthracnose symptoms. These isolates were further characterized based on morphology and multilocus phylogenetic analyses using partial DNA sequences at the ribosomal internal transcribed spacer regions and $\beta$-tubulin, actin, calmodulin, glyceraldehyde-3-phosphate dehydrogenase, and chitin synthase-encoding genes. The fungal isolates belong to five

However, C. fructicola was common and widely distributed species on leaves $(75.9 \%)$, followed by $C$. camelliae $(17.2 \%)$. There was no evidence of geographical specialization of the different species. Pathogenicity assays showed that all tested isolates, including 20 of C. camelliae, 11 of $C$. fructicola, four of $C$. siamense, two of $C$. aenigma, and one of $C$. gloeosporioides, were pathogenic to leaves and fruits of $\mathrm{Ca}$. oleifera. Among the five species, $C$. camelliae species showed strong pathogenicity on both leaves and fruits of $C a$. oleifera, and $C$. fructicola, $C$. siamense, $C$. aenigma, and $C$. gloeosporioides all showed weak pathogenicity on both leaves and fruits. No relationship was found between origin of isolates and their virulence. This is the first description of $C$. camelliae, $C$. fructicola, C. siamense, and C. gloeosporioides from the fruits of Ca. oleifera in China.
\end{abstract} species: C. camelliae, C. fructicola, C. siamense, C. aenigma, and C. gloeosporioides. C. camelliae was the most predominant and widely distributed species on fruits of Ca. oleifera (91.4\%), followed by $C$. fructicola $(6.3 \%)$.
Keywords: anthracnose, Camellia oleifera, multi-locus, pathogenicity, phylogenetic analyses
Tea-oil tree (Camellia oleifera Abel) is native to China and is considered one of the important edible oil woody plants. In China, this plant has been grown for approximately 2,300 years and is cultivated in 14 provinces (including province-level municipalities) of southern China (Deng and Xie 2008; Zhuang 2008). Statistical data for 2014 indicated that these plantations comprise over 3,800,000 hectares and produce 518,000 tons of edible oil (State Administration of Forestry of China 2016). Among the woody plant species for edible oil production, Ca. oleifera is valued equivalent to palm, olive, and coconut in the world. Camellia oil, extracted from $\mathrm{Ca}$. oleifera seeds, is regarded as high-quality edible oil because it has a high unsaturated fatty acid content, is rich in vitamins, and has a pleasant taste; camellia oil is also used for its medicinal properties to enhance human immunity, reduce low-density lipoprotein cholesterol, and prevent cardiovascular disease (Wang et al. 2017). The cultivation of $\mathrm{Ca}$. oleifera is also conducive to ecological and environmental protection from its deep taproot system and ability to grow in poor soil on hillsides not suitable for most other agricultural crops (Li et al. 2016; Wang et al. 2007). Thus, the development of Ca. oleifera is of great

${ }^{\dagger}$ Corresponding author: J. Huang; Junbinhuang@ mail.hzau.edu.cn

Funding: This work was supported by an Extension and Demonstration Project of Science and Technology in Forestry, Chinese Ministry of Finance (no. 2014HBTG05), a Hubei Province Technical Innovation Special Project (no. 2017ABA163), and a Science and Technology Supporting Project of the Hubei Department of Forestry (no. [2017]LYKJ03)

*The $\boldsymbol{e}$-Xtra logo stands for "electronic extra" and indicates that one supplementary table is published online.

The author(s) declare no conflict of interest.

Accepted for publication 10 August 2019

(C) 2020 The American Phytopathological Society significance for the national economy and the livelihood of local farmers in China.

The expanding cultivation of Ca. oleifera over the last several decades has also attracted increasing attention from plant pathologists to infectious diseases on this crop. Anthracnose is a serious disease in most fields of southern China, infecting leaves and fruits of $\mathrm{Ca}$. oleifera. Although historical records are not available, recent estimates suggested that it could generally cause a 20 to $40 \%$ fruit drop and up to $40 \%$ camellia seed loss in some plantations and could also lead to mortality of branches and sometimes even plants (Jin et al. 2009; Wu 1985). In the presence of appropriate moisture and ambient temperature in the fields of southern China, the disease can spread very quickly and is difficult to control; thus, it can result in severe economic losses and poses a huge threat to the $\mathrm{Ca}$. oleifera industry in China (Liu et al. 2009; Zhou et al. 2007).

The destructive pathogen causing anthracnose of $\mathrm{Ca}$. oleifera is in the Colletotrichum gloeosporioides species complex (Li et al. 2014), which is the causal agent of anthracnose disease on a wide range of subtropical and tropical agricultural crops and tree species in forests (Freeman et al. 1996). The taxonomy of Colletotrichum species has mainly relied on morphological characters and host range in the past (Hyde et al. 2009; Sutton 1980; von Arx 1957), such as conidial, conidiophore, and acervuli morphology (Freeman et al. 2000) and benomyl sensitivity (Valero et al. 2010). However, morphological differences are not sufficient to separate Colletotrichum species because there are variations for the same species when grown in the laboratory and the field under different growth conditions. Hence, molecular techniques are needed to differentiate Colletotrichum species and to examine genetic variation within and between species and populations (Cai et al. 2009; Hyde et al. 2009). Previous reports chiefly used the internal transcribed spacer (ITS) region of ribosomal DNA to separate Colletotrichum species (Freeman et al. 2000), but ITS alone was insufficient for distinguishing many closely related Colletotrichum species (Cannon et al. 2012; Damm et al. 2009; Weir et al. 2012). Multilocus markers, such as actin (ACT), $\beta$-tubulin (TUB2), chitin synthase 1 (CHSI), calmodulin (CAL), 
and glyceraldehyde-3-phosphate dehydrogenase (GAPDH) genes, have been used to resolve relationships among Colletotrichum species. For the $C$. gloeosporioides species complex, 22 species plus one subspecies have been accepted within this species complex using multilocus phylogenetic analyses together with morphological characteristics (Weir et al. 2012).

Based on recent progress in the classification of the $C$. gloeosporioides species complex and the lack of systematic information on the identity and characteristics of isolates causing tea-oil tree anthracnose in China, the objectives of this study were as follows: (i) identify the prevalence of Colletotrichum spp. associated with tea-oil tree anthracnose in the major production provinces in China based on morphology and phylogenetic analyses using multilocus sequences; (ii) examine virulence of different isolates and whether there are pathogenicity differences following the procedures as outlined through Koch's postulates; and (iii) investigate phylogenetic relationships among isolates of Colletotrichum spp. from tea-oil tree using sequences of ITS, ACT, TUB2, CHSI, CAL, and GAPDH.

\section{Materials and Methods}

Fungal isolation. Leaves and immature fruits of $\mathrm{Ca}$. oleifera with typical symptoms of anthracnose were collected from the main teaoil camellia production fields of eight provinces in southern China, including Anhui, Fujian, Guangdong, Guangxi, Hubei, Hunan, Jiangxi, and Zhejiang, respectively. Small sections $(3 \times 3 \mathrm{~mm})$ were cut from the margins of infected tissues and surface sterilized in $75 \%$ ethanol for $30 \mathrm{~s}$, then sterilized in $5 \%$ ( $\mathrm{vol} / \mathrm{vol}$ ) sodium hypochlorite for $1 \mathrm{~min}$, followed by three rinses with sterilized water, and finally dried on sterilized filter paper (Photita et al. 2005). The sections were then plated onto potato dextrose agar (PDA; 20\% diced potato, $2 \%$ glucose, $1.5 \%$ agar, and distilled water) plates and incubated at $25^{\circ} \mathrm{C}$. Fungal growth was examined daily for up to 6 days. Isolates were then transferred aseptically to fresh PDA and purified by single-spore culturing. All fungal isolates were placed on PDA slants and stored at $4^{\circ} \mathrm{C}$.

Morphological and cultural characterization. Isolates were cultured on PDA plates at $25^{\circ} \mathrm{C}$ for 5 days. Agar plugs $(6 \mathrm{~mm}$ in diameter) were aseptically cut from the periphery of actively growing cultures, transferred to the center of each 9-mm-diameter PDA plate, and incubated at $25^{\circ} \mathrm{C}$. Four replicate cultures of each isolate were investigated. Colony diameters were measured from 3 to 7 days and used to calculate the hyphal growth rate (in millimeters per day). The colony size and color of the conidial masses was also recorded.

After 10 days, most isolates produced conidia. For some nonsporulating isolates, sporulation on PDA was induced using the method of blocking mycelium as described by Peng and Shishiyama (1988). The size and shape of 30 conidia per isolate was recorded. Appressoria were induced by inoculation with conidia in two drops of distilled water on plastic coverslips inside Petri dishes containing moistened filter paper with sterile distilled water, which were incubated at $25^{\circ} \mathrm{C}$ in darkness (Prihastuti et al. 2009; Yang et al. 2009). After $24 \mathrm{~h}$, appressoria were formed at the ends of germ tubes and then measured. Conidia and appressoria were observed with a Nikon Eclipse $80 \mathrm{i}$ microscope using differential interference contrast illumination.

Extraction of fungal DNA. To obtain mycelia from Colletotrichum spp., a 6-mm-diameter plug from the growing margin of a 5day-old colony was inoculated at the center of a sterile cellophane membrane placed on PDA in a Petri dish $(90 \mathrm{~mm}$ in diameter) (Lou et al. 2015). The Petri dish was incubated at $25^{\circ} \mathrm{C}$ for 5 days. Fresh fungal mycelia of each isolate in the dish were collected from the colony surface with a spatula sterilized with a flame. The mycelia of each isolate were ground in liquid nitrogen with a mortar and pestle to a fine powder. Genomic DNA of the isolates was extracted by a cetyltrimethylammonium bromide method following Sambrook et al. (1989). The DNA samples were stored at $-20^{\circ} \mathrm{C}$.

PCR amplification and DNA sequencing. Gene sequences were obtained from six nuclear genes or regions, including ITS, TUB2, ACT, CAL, GAPDH, and CHSI (Table 1). The ITS, TUB2, ACT, CAL, GAPDH, and CHSI genes or regions were amplified with pairs of primers ITS1 and ITS4 (White et al. 1990), T1 and Bt2b (Glass and Donaldson 1995), ACT512F and ACT783R (Carbone and Kohn 1999), CL1C and CL2C (Weir et al. 2012), GDF and GDR (Templeton et al. 1992), and CHS-79F and CHS-345R (Carbone and Kohn 1999), respectively. All primers were synthesized by Tsingke Biotechnology Co., Ltd. (Wuhan, China).

All PCR amplifications were conducted in 50- $\mu 1$ reaction volumes, containing $1 \times$ PCR Ex-buffer $\left(\mathrm{MgCl}_{2}\right.$ plus), $0.2 \mathrm{mM}$ concentrations of each dNTP, $0.5 \mathrm{mM}$ concentrations of each primer, 1 unit of Ex-Taq DNA polymerase (Takara, Dalian, China), and $2 \mu \mathrm{l}$ of template DNA $(10 \mathrm{ng} / \mu \mathrm{l})$. Amplification was performed in a PCR Thermal Cycler (TP600; Takara). The PCR program for the ITS region included a denaturing step at $95^{\circ} \mathrm{C}$ for $5 \mathrm{~min}$, followed by 35 cycles at $94^{\circ} \mathrm{C}$ for $1 \mathrm{~min}, 55^{\circ} \mathrm{C}$ for $1 \mathrm{~min}, 72^{\circ} \mathrm{C}$ for $1 \mathrm{~min}$, and a final cycle of $10 \mathrm{~min}$ at $72^{\circ} \mathrm{C}$. The PCR amplification for TUB2, CAL, ACT, GAPDH, and CHSI was conducted as described by Weir et al. (2012) but modified by using an annealing temperature of $59^{\circ} \mathrm{C}$ for TUB 2 and $\mathrm{CAL}, 58^{\circ} \mathrm{C}$ for $\mathrm{ACT}$, and $56^{\circ} \mathrm{C}$ for GAPDH and CHSI. The amplification products were analyzed on a $1.0 \%$ agarose gel in Tris/borate/EDTA buffer and purified. Sequencing was conducted by Sangon Biotechnology Co., Ltd. (Shanghai, China).

Phylogenetic analyses. Sequences of Colletotrichum isolates in this study were submitted to GenBank. The accession numbers of all sequences are listed in Supplementary Table S1. The nucleotide diversity of each gene within $C$. camelliae and $C$. fructicola was analyzed with DnaSP version 5 software (Librado and Rozas 2009). GenAlEx 6.5 was used to calculate the number of alleles at each locus

Table 1. Primers used for PCR amplification and sequencing, and each of the genes for C. camelliae and C. fructicola

\begin{tabular}{|c|c|c|c|c|c|c|c|c|c|c|}
\hline \multirow[b]{2}{*}{$\mathrm{Gene}^{\mathrm{Z}}$} & \multirow[b]{2}{*}{ Primer } & \multirow[b]{2}{*}{ Primer sequence $\left(5^{\prime}\right.$ to $\left.3^{\prime}\right)$} & \multirow[b]{2}{*}{$\begin{array}{c}\text { Gene } \\
\text { length } \\
\text { (bp) }\end{array}$} & \multicolumn{3}{|c|}{ C. camelliae } & \multicolumn{3}{|c|}{ C. fructicola } & \multirow[b]{2}{*}{ Reference } \\
\hline & & & & $\begin{array}{c}\text { Nucleotide } \\
\text { diversity }\end{array}$ & $\begin{array}{c}\text { Alleles } \\
(n)\end{array}$ & $\begin{array}{l}\text { Multilocus } \\
\text { genotypes } \\
(n)\end{array}$ & $\begin{array}{c}\text { Nucleotide } \\
\text { diversity }\end{array}$ & $\begin{array}{c}\text { Alleles } \\
(n)\end{array}$ & $\begin{array}{l}\text { Multilocus } \\
\text { genotypes } \\
(n)\end{array}$ & \\
\hline ITS & $\begin{array}{l}\text { ITS-1 } \\
\text { ITS-4 }\end{array}$ & $\begin{array}{l}\text { TCCGTAGGTGAACCTGCGG } \\
\text { TCCTCCGCTTATTGATATGC }\end{array}$ & 540 & 0.00152 & 14 & 61 & 0.00079 & 9 & 42 & White et al. (1990) \\
\hline ACT & $\begin{array}{l}\text { ACT-512F } \\
\text { ACT-783R }\end{array}$ & $\begin{array}{l}\text { ATGTGCAAGGCCGGTTTCGC } \\
\text { TACGAGTCCTTCTGGCCCAT }\end{array}$ & $233-235$ & 0.00763 & 13 & & 0.00138 & 6 & & Carbone and Kohn (1999) \\
\hline CAL & $\begin{array}{l}\text { CL1C } \\
\text { CL2C }\end{array}$ & $\begin{array}{l}\text { GAATTCAAGGAGGCCTTCTC } \\
\text { CTTCTGCATCATGAGCTGGAC }\end{array}$ & $725-735$ & 0.00003 & 4 & & 0.00015 & 5 & & Weir et al. (2012) \\
\hline CHSI & $\begin{array}{l}\text { CHS-79F } \\
\text { CHS- } 345 \text { R }\end{array}$ & $\begin{array}{l}\text { TGGGGCAAGGATGCTTGGAAGAAG } \\
\text { TGGAAGAACCATCTGTGAGAGTTG }\end{array}$ & $251-262$ & 0.00756 & 7 & & 0.00226 & 5 & & Carbone and Kohn (1999) \\
\hline TUB2 & $\mathrm{T} 1$ & $\begin{array}{l}\text { AACATGCGTGAGATTGTAAGT } \\
\text { ACCCTCAGTGTAGTGACCCTTGGC }\end{array}$ & $710-725$ & 0.00015 & 11 & & 0.00036 & 4 & & $\begin{array}{l}\text { Glass and Donaldson (1995); } \\
\text { O'Donnell and Cigelnik (1997) }\end{array}$ \\
\hline GAPDH & $\begin{array}{l}\text { GDF } \\
\text { GDR }\end{array}$ & $\begin{array}{l}\text { GCCGTCAACGACCCCTTCATTGA } \\
\text { GGGTGGAGTCGTACTTGAGCATGT }\end{array}$ & $231-236$ & 0.00185 & 6 & & 0.00806 & 11 & & Templeton et al. (1992) \\
\hline
\end{tabular}

${ }_{\mathrm{z}}$ ITS $=$ internal transcribed spacer, ACT $=$ actin, $\mathrm{CAL}=$ calmodulin, CHSI $=$ chitin synthase $1, \mathrm{TUB} 2=\beta$-tubulin, and GAPDH $=$ glyceraldehyde-3-phosphate dehydrogenase. 
and the number of multilocus genotypes within $C$. camelliae and $C$. fructicola (Peakall and Smouse 2006). The sequences of each individual locus were analyzed using BLASTN against the GenBank database to investigate whether the isolates belonged to the $C$. gloeosporioides complex. However, the blasting result of the sequences of each individual locus showed insufficient data to determine closely related species within the $C$. gloeosporioides complex. Thus, the concatenated sequences of the six gene fragments (ITS-TUB2-ACT-CAL-CHSI-GAPDH) were used to determine the species status following the phylogenetic approaches as recommended in previous studies (Fu et al. 2019). Sequences of each isolate were edited and assembled using DNAMAN (version 5.2; Lynnon Biosoft) and aligned by ClustalX version 1.83 (Larkin et al. 2007) to produce consensus sequences that were compared by BLAST (Altschul et al. 1990) against the NCBI database. Sequences from ex-type or ex-epitype isolates of Colletotrichum species from GenBank were selected for use in the phylogenetic analyses. Alignments were checked and manual adjustments were made where necessary. A maximum likelihood analysis was performed on the multilocus alignment using MEGA software (version 5.0). Clade stability was assessed in a bootstrap analysis with 1,000 replicates.

Virulence test. Thirty-eight isolates, including 20 of C. camelliae, 11 of $C$. fructicola, four of $C$. siamense, two of C. aenigma, and one of $C$. gloeosporioides, were selected for virulence tests on detached leaves and fruits of $\mathrm{Ca}$. oleifera under controlled conditions. Isolates were incubated on PDA plates for 7 days at $25^{\circ} \mathrm{C}$ in the laboratory and conidia were obtained as previously described. The conidial suspension was adjusted to $2.0 \times 10^{6}$ conidia/ml with sterile distilled

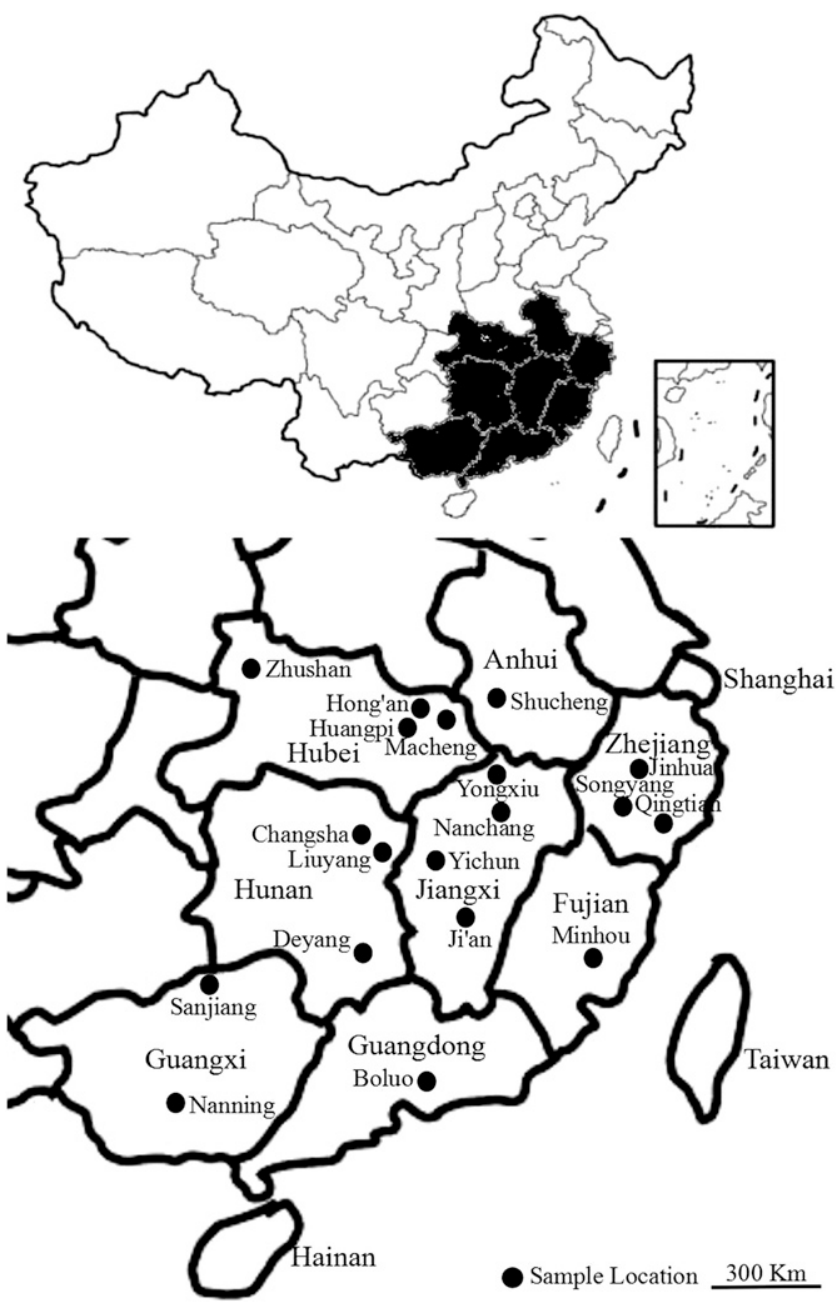

Fig. 1. An outline map of the locations of the collections of Colletotrichum isolates. This map shows the geographic locations where samples of Colletotrichum spp. associated with Camellia oleifera anthracnose were collected from plantations in eight provinces in southern China. water. Fresh young leaves and fresh immature fruits without disease from Wuhan, Hubei were used for inoculation. Before inoculation, the leaves and fruits were first washed with running water, surface sterilized in $75 \%$ ethanol, and finally rinsed with sterile distilled water.

After washing and air drying, detached healthy leaves were placed on a layer of moist absorbent paper in an enamel basin $(500 \times 350 \times$ $40 \mathrm{~mm}$ ). The method of inoculation with stab injury was used to avoid leaves decaying before the virulence test was completed. Two piercing wounds of each leaf were made in the midregion forming a tiny little dot using a sterilized needle. Each piercing wound was inoculated with a $10-\mu l$ droplet of conidial suspension. Ten leaves were inoculated for each isolate and leaves were treated with sterile water as controls. The enamel basins were sealed by plastic film and incubated in a growth chamber at $25^{\circ} \mathrm{C}$. Virulence was assessed by measuring lesion length at 8 days postinoculation (dpi) in two perpendicular directions on each leaf.

After washing and air drying, detached immature healthy fruits were wounded on the surface by piercing with a sterilized needle. A 10- $\mu$ l droplet of a conidial suspension was placed on the wound sites. Ten fruits were inoculated for each isolate and sterile water was used for control treatments. Inoculated fruits were placed in a sealed plastic carton $(300 \times 200 \times 200 \mathrm{~mm})$ with a layer of moist absorbent paper to maintain humidity. The sealed plastic cartons were incubated in a growth chamber at $25^{\circ} \mathrm{C}$. Fruits were checked for development of symptoms for up to 20 days. Virulence was evaluated by measuring lesion length at $20 \mathrm{dpi}$ in two perpendicular directions.

Statistical analysis. The data from all quantitative assays were analyzed with DPS statistical analysis software (version 3.01; China Agricultural Press, Beijing, China), using analysis of variance. When significant treatment effects were found $(P<0.05)$, the multiple comparison was analyzed using the test of least significant difference.

\section{Results}

Fungal isolation. From 2012 to 2017, 272 plant samples exhibiting anthracnose symptoms were collected from eight provinces in China (Fig. 1). At least one isolate from each field was chosen for further analysis. In total, 232 Colletotrichum isolates were obtained and subjected to single-spore isolation, including 58 isolates from leaves and 174 isolates from fruits (Supplementary Table S1). Among the 58 isolates from leaves, 44 were identified as $C$. fructicola, 10 as $C$. camelliae, two as $C$. siamense, and two as $C$. aenigma. Among the 174 isolates from fruits, 159 were identified as $C$. camelliae, 11 as $C$. fructicola, three as $C$. siamense, and one as $C$. gloeosporioides s.s. During the isolation, other species from genera such as Botryosphaeria, Alternaria, and Phomopsis were also isolated, but those were not further studied for the time being.

Phylogenetic analyses. ITS, TUB2, ACT, CAL, GAPDH, and CHSI genes or regions of all isolates were successfully amplified and sequenced. The sequences at the individual locus were insufficient to separate closely related species within the $C$. gloeosporioides species complex. Thus, the six genes or regions of each isolate were combined in the order of ITS-TUB2-ACT-CAL-CHSI-GAPD. The lengths of the individual gene sequences included in the alignment were as follows: ITS (540 bp), TUB2 (710 to $725 \mathrm{bp}$ ), ACT (233 to $235 \mathrm{bp}$ ), CAL ( 725 to $735 \mathrm{bp}$ ), CHSI ( 251 to $262 \mathrm{bp}$ ), and GAPDH (231 to $236 \mathrm{bp}$ ).

A maximum likelihood tree of 174 Colletotrichum isolates from fruits in this study and sequences from ex-type or ex-epitype isolates from GenBank using combined ITS, TUB2, ACT, CAL, GAPDH, and CHSI genes is shown in Figure 2. The combined data set produced four well- separated clades. A total of 159 isolates in our samples belonged to one clade (82\% bootstrap support) along with $C$. camelliae ICMP10646 and ICMP 18542 from Camellia sasanqua in the United States and ICMP 10643 from Camellia $\times$ williamsii in the United Kingdom. Eleven of our isolates belonged to the second clade (90\% bootstrap support) along with $C$. fructicola ICMP 18631 from Limonium sinuatum in Israel and ICMP 18727 from Fragaria $\times$ ananassa in the United States. Three isolates (GXNN-27, GXNN-23, and HNCS-41) belonged to the third clade (95\% bootstrap support) 
as represented by $C$. siamense ICMP 12567 from Persea americana in Australia and ICMP 18121 from Dioscorea rotundata in Nigeria. One isolate (JXYX-34) belonged to the fourth clade (100\% bootstrap support) with C. gloeosporioides s.s. ICMP 17821 and CBS 953.97 from Citrus sinensis in Italy.

A phylogenetic tree of 58 Colletotrichum isolates from leaves in this study also produced four well-separated clades (Fig. 3). Forty- four isolates belonged to one clade along with $C$. fructicola ICMP 18631 from $L$. sinuatum in Israel and ICMP 18727 from Fragaria $\times$ ananassa in the United States. Ten isolates belonged to the second clade along with $C$. camelliae ICMP 10646 and ICMP 18542 from Ca. sasanqua in the United States and ICMP 10643 from $C a . \times$ williamsii in the United Kingdom. Two isolates (HBHP-4 and HBHP-5) belonged to the third clade along with $C$. aenigma ICMP 18608 from

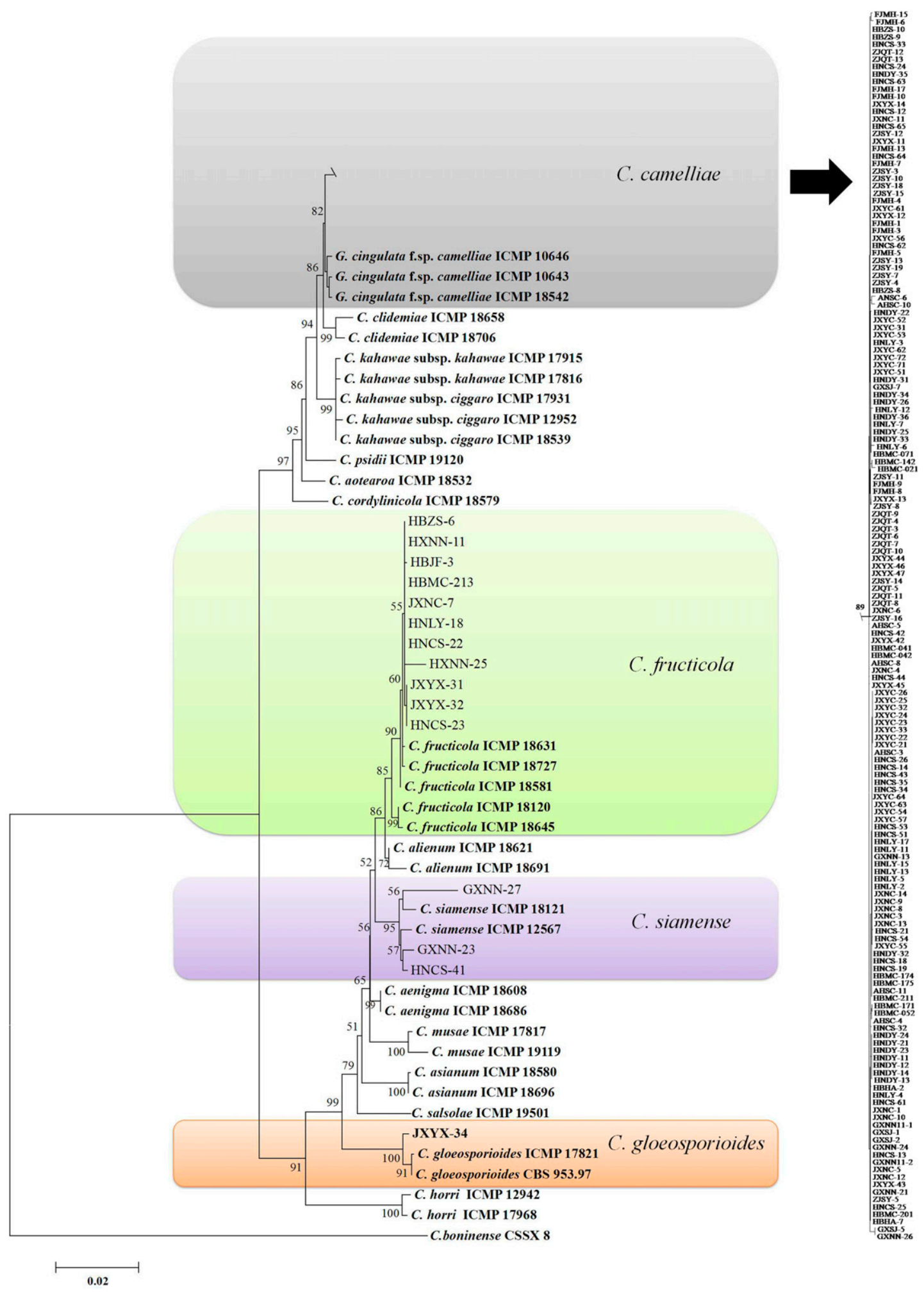

Fig. 2. Phylogenetic tree using sequences of 174 Colletotrichum isolates from tea-oil tree fruits in southern China and from ex-type isolates of Colletotrichum species from GenBank using concatenated internal transcribed spacer, $\beta$-tubulin, actin, calmodulin, glyceraldehyde-3-phosphate dehydrogenase, and chitin synthase 1 genes. C. camelliae, C. fructicola, C. siamense, and C. gloeosporioides s.s. were grouped in the tree, respectively. Bootstrap values $>50 \%(1,000$ replications) are given at the nodes. Ex-type isolates are in bold. Shaded blocks indicate clades containing isolates from tea-oil tree fruits. $C$. boninense was used as the outgroup. 
Persea americana in Israel and ICMP 18686 from Pyrus pyrifolia in Japan. Lastly, two isolates (GDBL-6 and GDBL-7) belonged to the fourth clade with $C$. siamense ICMP 12567 from $P$. americana in Australia and ICMP 18121 from $D$. rotundata in Nigeria.

The results of gene sequence clustering analysis showed that five Colletotrichum species were isolated from anthracnose samples of Ca. oleifera in this study. C. camelliae, C. fructicola, and C. siamense were all isolated from both fruits and leaves of $\mathrm{Ca}$. oleifera.
However, $C$. gloeosporioides s.s. was only isolated from fruits and C. aenigma was only isolated from leaves in our study. Among all isolates from $\mathrm{Ca}$. oleifera fruits, $C$. camelliae was the most frequently isolated species, comprising $91 \%$ of all isolates, followed by $C$. fructicola at $6 \%, C$. siamense at $2 \%$, and $C$. gloeosporioides s.s. at $1 \%$. However, $C$. fructicola was the most frequently isolated species from Ca. oleifera leaves, comprising $76 \%$ of all isolates, followed by $C$. camelliae at $18 \%$, C. siamense at $3 \%$, and C. aenigma at $3 \%$.

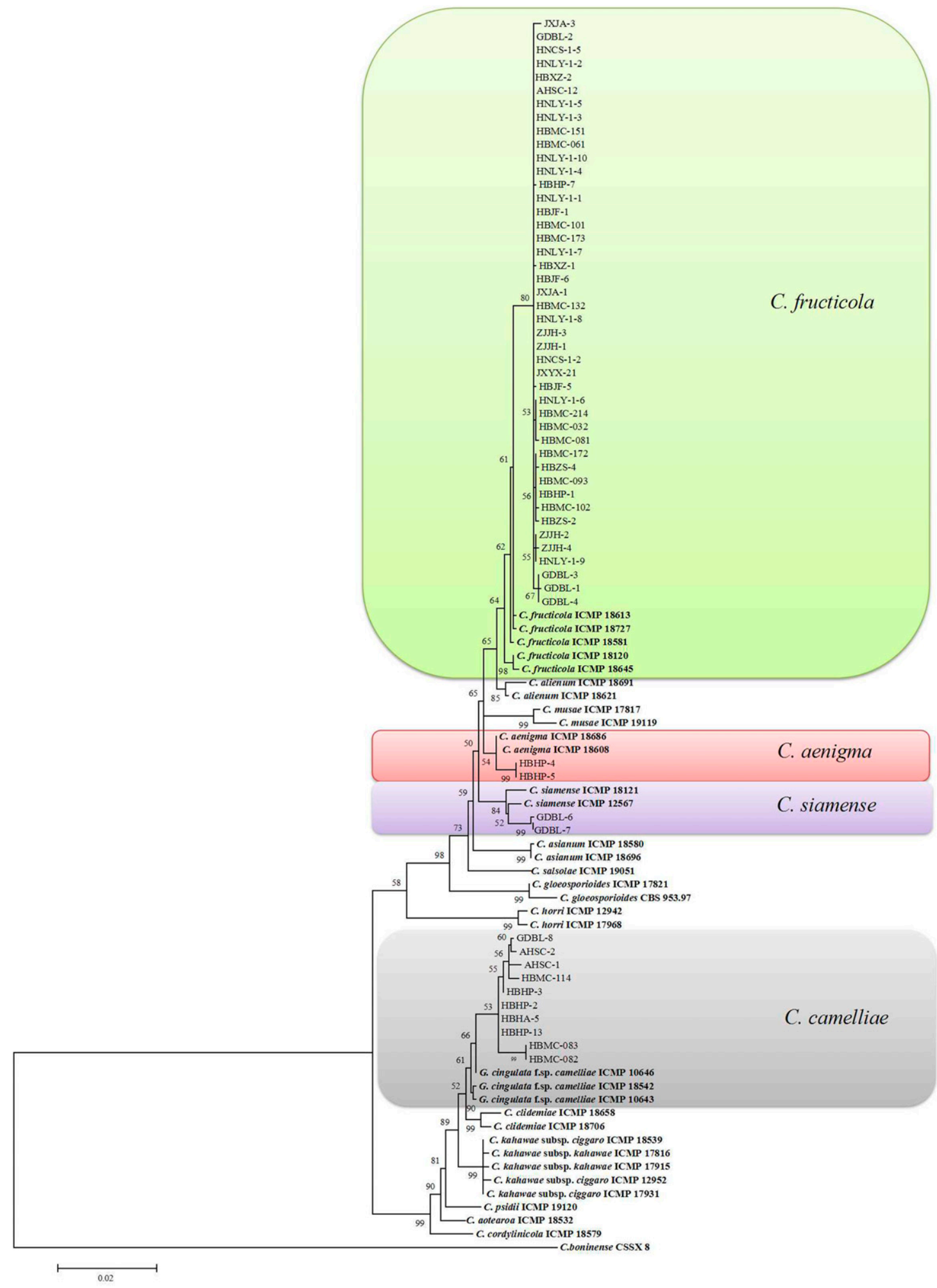

Fig. 3. Phylogenetic tree using sequences of 58 Colletotrichum isolates from tea-oil tree leaves in southern China and from ex-type isolates of Colletotrichum species from GenBank using concatenated internal transcribed spacer, $\beta$-tubulin, actin, calmodulin, glyceraldehyde-3-phosphate dehydrogenase, and chitin synthase 1 genes. C. fructicola, C. camelliae, C. siamense, and $C$. aenigma were grouped in the tree, respectively. Bootstrap values $>50 \%$ (1,000 replications) are given at the nodes. Ex-type isolates are in bold. Shaded blocks indicate clades containing isolates from tea-oil tree leaves. C. boninense was used as the outgroup. 
The nucleotide diversity and allele number within C. fructicola and $C$. camelliae were different at each locus (Table 1). For C. camelliae, the highest nucleotide diversity was found in the ACT gene fragment, followed by CHSI, GAPDH, ITS, TUB2, and CAL. For $C$. fructicola, the highest nucleotide diversity was found in the GAPDH gene fragment, followed by CHSI, ACT, ITS, TUB2, and CAL. For ITS, ACT, CAL, CHSI, TUB2, and GAPDH, the allele numbers at each locus in the total samples of $C$. camelliae were 14, 13, 4, 7, 11 , and 6 , and those of $C$. fructicola were $9,6,5,5,4$, and 11 , respectively. There were 61 multilocus genotypes of $C$. camelliae and 42 of C. fructicola.

Morphological and cultural characterization. Thirty-eight representative isolates were selected for observation of their morphological and cultural characterization in the study, including 20 of $C$. camelliae, 11 of $C$. fructicola, four of $C$. siamense, two of $C$. aenigma, and one of $C$. gloeosporioides. Few differences in colony morphology were obviously observed among the five species identified when grown on PDA (Fig. 4). All selected isolates first developed white colonies that became gray to black after 7 days. Orange conidial masses were often observed on $C$. camelliae colonies and at the center of $C$. siamense colonies. Colony sectoring was occasionally observed in several isolates. There was considerable variation in mycelial growth rate among the selected isolates. The average mycelial growth rate of $C$. fructicola and $C$. siamense was generally faster than the other three species (Table 2). The average mycelial growth rate was $13.6 \pm 0.6 \mathrm{~mm} /$ day for $C$. fructicola $(n=11), 13.5 \pm 0.8 \mathrm{~mm} /$ day for $C$. siamense $(n=4)$, and $11.5 \pm 1.1 \mathrm{~mm} /$ day for $C$. camelliae $(n=20)$, and there were significant differences among $C$. fructicola,

\section{C. camelliae}

C. fructicola

C. siamense

A
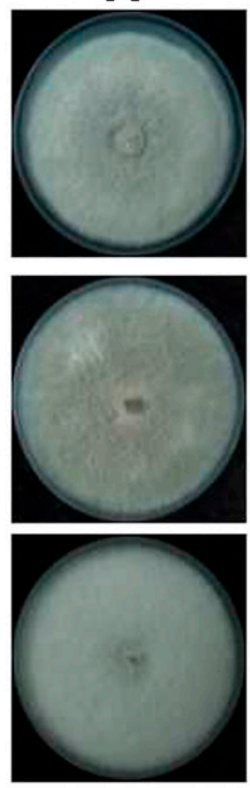

C. aenigma
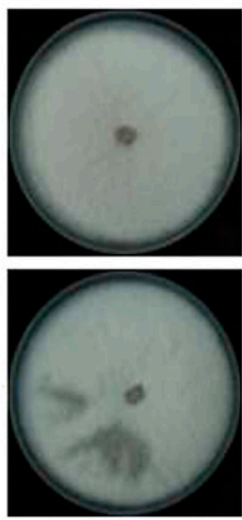

\section{C. gloeosporioides}

B
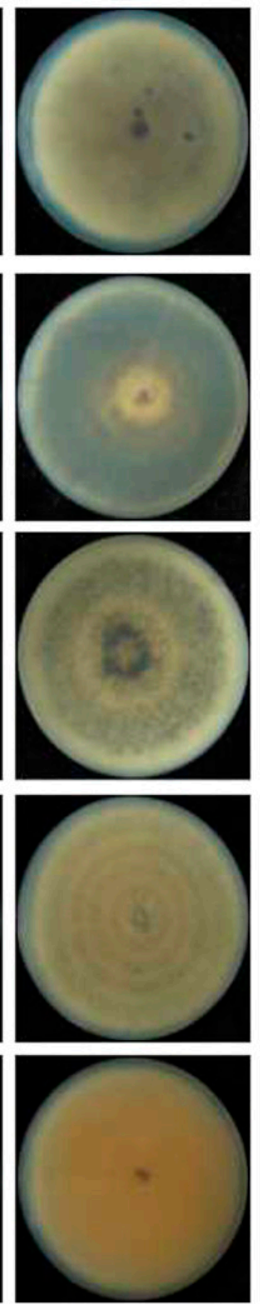
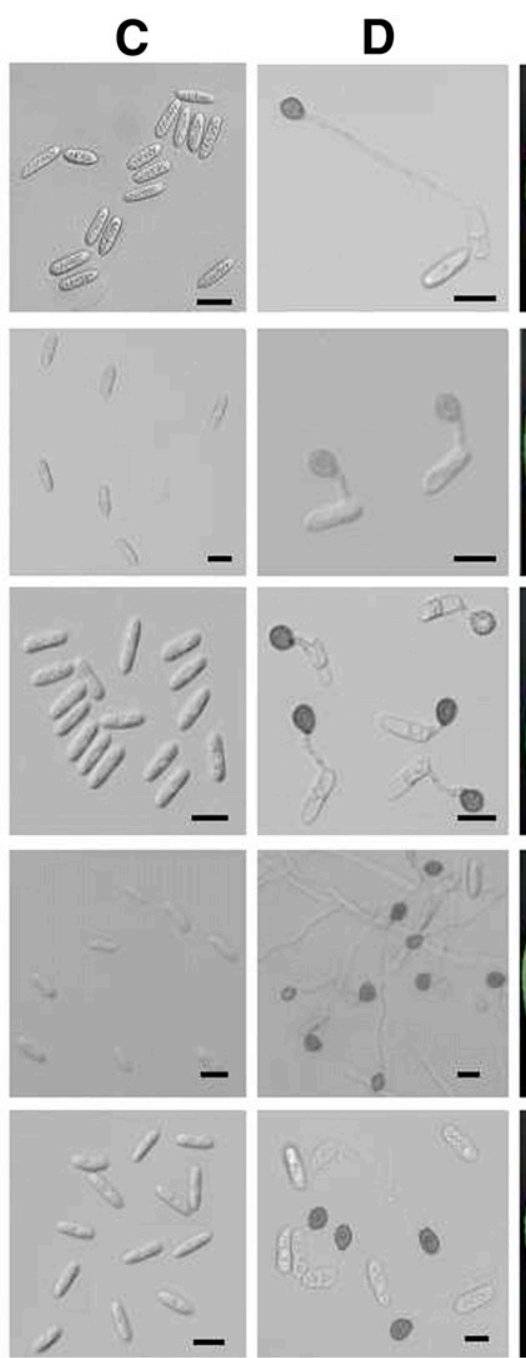
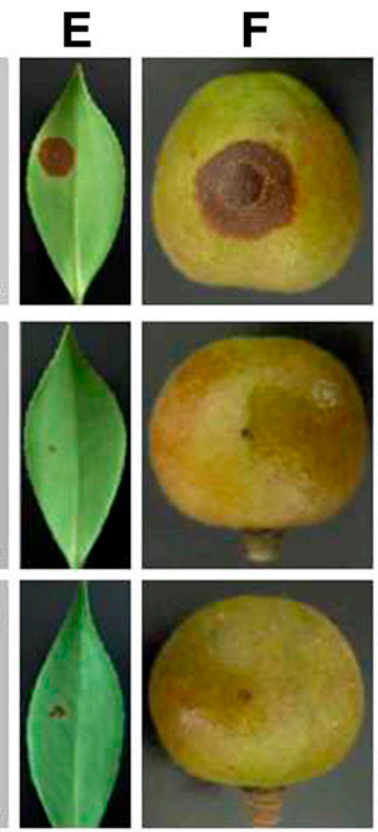

Fig. 4. Cultural characteristics and pathogenicity of five Colletotrichum species from tea-oil tree. The colony morphology was observed growing on potato dextrose agar at $25^{\circ} \mathrm{C}$ for 6 days. The symptoms were caused by Colletotrichum species on leaves at day 8 after inoculation and on fruits at day 20 after inoculation with conidia. A, Top view. B, Reverse view. C, Conidia. D, Appressorium. E, Symptom on leaf. F, Symptom on fruit. Bar $=10 \mu \mathrm{m}$.

Table 2. Morphological and virulence descriptions of five Colletotrichum species from tea-oil tree ${ }^{\mathrm{z}}$

\begin{tabular}{lccc}
\hline & & & \multicolumn{2}{c}{ Lesion diameter $(\mathbf{m m})$} \\
\cline { 3 - 4 } Species & Conidial size $(\boldsymbol{\mu m})$ & Mycelial growth $(\mathbf{m m} / \mathbf{d a y})$ & Leaves \\
\hline C. camelliae & $15.8 \pm 1.1 \times 5.3 \pm 0.5 \mathrm{a}$ & $11.5 \pm 1.1 \mathrm{~b}$ & $6.4 \pm 1.4 \mathrm{a}$ \\
C. fructicola & $15.9 \pm 0.8 \times 5.2 \pm 0.4 \mathrm{a}$ & $13.6 \pm 0.6 \mathrm{a}$ & $1.6 \pm 1.7 \mathrm{bc}$ \\
C. siamense & $15.6 \pm 1.0 \times 5.1 \pm 0.1 \mathrm{a}$ & $13.5 \pm 0.8 \mathrm{a}$ & $3.5 \pm 3.1 \mathrm{~b}$ \\
C. aenigma & $16.2 \pm 0.5 \times 5.0 \pm 0.1 \mathrm{a}$ & $12.7 \pm 0.6 \mathrm{ab}$ & $1.4 \pm 0.1 \mathrm{bc}$ \\
C. gloeosporioides & $16.8 \pm 2.0 \times 5.3 \pm 0.4 \mathrm{a}$ & $12.1 \pm 0.3 \mathrm{~b}$ & $1.5 \pm 0.2 \mathrm{~b}$ \\
\hline
\end{tabular}

${ }^{\mathrm{z}}$ Lowercase letters indicate significant treatment effects $(P<0.05)$. 
C. siamense, and C. camelliae (Table 3 ). Conidia were all hyaline, guttulate, smooth, one celled, and cylindrical. The average conidial sizes for isolates were 13.7 to $17.9 \times 4.6$ to $6.0 \mu \mathrm{m}$ for $C$. camelliae, 14.5 to $17.1 \times 4.7$ to $5.9 \mu \mathrm{m}$ for $C$. fructicola, and 14.2 to $16.7 \times 4.9$ to $5.1 \mu \mathrm{m}$ for $C$. siamense. However, there were no significant differences in the conidial sizes among the species.

Virulence. All 38 tested isolates were pathogenic to wounded leaves and fruits of $\mathrm{Ca}$. oleifera. Infected leaves and fruits developed sunken, dark brown to black, and necrotic lesions. The control had no symptoms on both leaves and fruits. Typical orange conidial masses were not observed on leaves at $8 \mathrm{dpi}$ but were often observed on fruits at 20 dpi. Disease severity caused by the isolates showed significant differences (Table 3 ). Isolates of $C$. camelliae species showed generally strong virulence on both leaves and fruits. Among the isolates of C. camelliae, the virulence of different isolates had a certain difference, and lesion diameter ranged from 3.5 to $9.4 \mathrm{~mm}$ on leaves and from 2.4 to $12.8 \mathrm{~mm}$ on fruits. Isolates of $C$. fructicola, $C$. siamense, C. aenigma, and C. gloeosporioides s.s. showed generally weak virulence on both leaves and fruits, whereas $C$. fructicola isolate GDBL-2 and $C$. siamense isolate GXNN-27 showed higher virulence on leaves, with lesion diameters of 6.7 and $7.6 \mathrm{~mm}$, respectively. There were significant differences of virulence at the species level (Table 2). C. camelliae showed the strongest virulence on both leaves and fruits, with lesion diameters of 6.4 and $8.3 \mathrm{~mm}$, respectively, whereas the other species showed much weaker virulence on both leaves and fruits, with lesion diameters $\leq 3.5$ and $\leq 2.3 \mathrm{~mm}$, respectively.

\section{Discussion}

Since $C$. gloeosporioides was originally reported as the pathogen of the Citrus disease in Italy, many morphologically similar species have been included in the C. gloeosporioides species complex (Liu et al. 2013; Penzig 1882). Phylogenetically distinct species were proposed from the complex by multilocus gene phylogenetic analysis,

Table 3. Morphological and virulence descriptions of Colletotrichum isolates from tea-oil tree in China

\begin{tabular}{|c|c|c|c|c|}
\hline \multirow[b]{2}{*}{ Isolate } & \multirow[b]{2}{*}{ Conidial size $(\mu \mathbf{m})^{x}$} & \multirow[b]{2}{*}{ Mycelial growth (mm/day)y } & \multicolumn{2}{|c|}{ Lesion diameter $(\mathbf{m m})^{\mathrm{z}}$} \\
\hline & & & Leaves & Fruits \\
\hline \multicolumn{5}{|l|}{ C. camelliae } \\
\hline HBMC-171 & $15.8 \pm 0.8 \times 5.7 \pm 0.5$ & $12.3 \mathrm{hij}$ & $7.6 \mathrm{abc}$ & $12.6 \mathrm{~b}$ \\
\hline HBMC-175 & $15.5 \pm 1.3 \times 6.0 \pm 0.6$ & $12.2 \mathrm{ij}$ & $7.2 \mathrm{abc}$ & 10.8 cde \\
\hline HBHР-13 & $16.4 \pm 1.1 \times 5.4 \pm 0.4$ & 12.4 hij & 3.5 efghij & 10.0 efg \\
\hline HBHA-5 & $13.7 \pm 1.2 \times 4.6 \pm 0.5$ & $10.8 \mathrm{n}$ & 5.9 bcde & $3.5 \mathrm{jk}$ \\
\hline ZJSY-18 & $15.9 \pm 1.9 \times 4.9 \pm 0.5$ & $11.2 \mathrm{i}$ & 6.4 abcde & $11.0 \mathrm{cde}$ \\
\hline ZJSY-8 & $14.1 \pm 1.4 \times 4.8 \pm 0.3$ & $10.3 \mathrm{p}$ & $9.4 \mathrm{a}$ & $9.3 \mathrm{fg}$ \\
\hline ZJQT-4 & $15.4 \pm 0.9 \times 4.9 \pm 0.3$ & $11.6 \mathrm{im}$ & 5.1cdef & $6.5 \mathrm{i}$ \\
\hline ZJQT-7 & $16.0 \pm 1.3 \times 5.1 \pm 0.4$ & 10.5 o & 5.9 bcde & $14.2 \mathrm{a}$ \\
\hline ZJQT-11 & $15.7 \pm 1.0 \times 5.1 \pm 0.4$ & $10.0 \mathrm{q}$ & $6.8 \mathrm{abcd}$ & 10.5 cdef \\
\hline JXNC-1 & $17.1 \pm 1.2 \times 5.7 \pm 0.5$ & $12.8 \mathrm{cdef}$ & $7.1 \mathrm{abcd}$ & $9.3 \mathrm{fg}$ \\
\hline JXNC-14 & $16.2 \pm 1.2 \times 5.1 \pm 0.4$ & $9.1 \mathrm{~s}$ & 4.9 cdefg & $10.3 \mathrm{def}$ \\
\hline JXYX-14 & $15.0 \pm 1.4 \times 5.9 \pm 0.5$ & $13.0 \mathrm{cde}$ & $7.8 \mathrm{abc}$ & $2.5 \mathrm{klmn}$ \\
\hline JXYX-42 & $14.6 \pm 1.3 \times 4.8 \pm 0.3$ & $12.4 \mathrm{hi}$ & 5.8 bcdef & $3.2 \mathrm{jkl}$ \\
\hline GXSJ-7 & $14.7 \pm 0.8 \times 5.4 \pm 0.3$ & $10.8 \mathrm{n}$ & 6.5 abcde & $7.7 \mathrm{hi}$ \\
\hline GXNN11-1 & $15.5 \pm 1.0 \times 5.8 \pm 0.4$ & $12.6 \mathrm{fg}$ & 5.9 bcde & $11.7 \mathrm{bc}$ \\
\hline GXNN11-2 & $17.3 \pm 1.0 \times 5.5 \pm 0.3$ & $12.3 \mathrm{hij}$ & 6.0 bcde & $2.4 \mathrm{klmn}$ \\
\hline GXNN24 & $17.9 \pm 1.5 \times 5.5 \pm 0.4$ & $12.9 \mathrm{cdef}$ & $8.7 \mathrm{ab}$ & $2.7 \mathrm{klm}$ \\
\hline HNCS-12 & $17.2 \pm 1.1 \times 5.4 \pm 0.4$ & $10.8 \mathrm{n}$ & 5.8 bcdef & $11.3 \mathrm{~cd}$ \\
\hline HNCS-52 & $15.6 \pm 1.3 \times 5.3 \pm 0.5$ & $10.9 \mathrm{mn}$ & $5.3 \mathrm{cdef}$ & $12.8 \mathrm{~b}$ \\
\hline HNLY-7 & $16.9 \pm 1.0 \times 5.4 \pm 0.6$ & $11.6 \mathrm{k}$ & 5.7 cdef & $4.0 \mathrm{j}$ \\
\hline \multicolumn{5}{|l|}{ C. fructicola } \\
\hline HBMC-173 & $15.8 \pm 1.6 \times 5.4 \pm 0.4$ & $14.2 \mathrm{a}$ & $1.3 \mathrm{hij}$ & $1.8 \mathrm{mn}$ \\
\hline HBMC-151 & $15.6 \pm 1.3 \times 5.0 \pm 0.5$ & $14.2 \mathrm{a}$ & 1.9 ghij & $\mathrm{N}$ \\
\hline HBHP-7 & $16.6 \pm 1.3 \times 4.9 \pm 0.3$ & $13.0 \mathrm{~cd}$ & $1.3 \mathrm{hij}$ & $1.6 \mathrm{mn}$ \\
\hline JXJA-1 & $17.1 \pm 1.5 \times 5.4 \pm 0.3$ & $13.6 \mathrm{~b}$ & $0.9 \mathrm{ij}$ & $1.4 \mathrm{n}$ \\
\hline JXJA-2 & $16.5 \pm 1.7 \times 5.4 \pm 0.3$ & $13.5 \mathrm{~b}$ & $0.8 \mathrm{ij}$ & $1.4 \mathrm{n}$ \\
\hline JXYX-21 & $16.5 \pm 1.1 \times 5.6 \pm 0.5$ & $12.9 \mathrm{cde}$ & $1.1 \mathrm{ij}$ & $1.5 \mathrm{mn}$ \\
\hline JXNC-7 & $14.8 \pm 1.3 \times 5.0 \pm 0.4$ & $12.6 \mathrm{gh}$ & $1.6 \mathrm{hij}$ & $1.3 \mathrm{n}$ \\
\hline HNCS-1-2 & $14.5 \pm 1.0 \times 4.7 \pm 0.4$ & $13.6 \mathrm{~b}$ & $0.7 \mathrm{ij}$ & $1.3 \mathrm{n}$ \\
\hline HNLY-18 & $15.6 \pm 1.4 \times 5.0 \pm 0.4$ & $14.2 \mathrm{a}$ & $0.6 \mathrm{j}$ & $1.5 \mathrm{mn}$ \\
\hline GDBL-2 & $16.4 \pm 1.3 \times 5.9 \pm 0.4$ & $14.2 \mathrm{a}$ & $6.7 \mathrm{abcd}$ & $1.7 \mathrm{mn}$ \\
\hline GXNN-25 & $15.7 \pm 0.9 \times 5.3 \pm 0.4$ & $13.9 \mathrm{a}$ & $0.9 \mathrm{ij}$ & $1.4 \mathrm{n}$ \\
\hline \multicolumn{5}{|l|}{ C. siamense } \\
\hline GXNN-27 & $15.9 \pm 1.5 \times 5.1 \pm 0.3$ & $14.2 \mathrm{a}$ & $7.6 \mathrm{abc}$ & $1.5 \mathrm{mn}$ \\
\hline GXNN-23 & $14.2 \pm 2.0 \times 4.9 \pm 0.5$ & $12.9 \mathrm{cde}$ & 1.7 hij & $1.4 \mathrm{n}$ \\
\hline HNCS-41 & $16.7 \pm 1.5 \times 5.1 \pm 0.5$ & $14.2 \mathrm{a}$ & 4.1defgh & $1.5 \mathrm{mn}$ \\
\hline GDBL-7 & $15.5 \pm 1.2 \times 5.1 \pm 0.4$ & $12.8 \mathrm{cdef}$ & $0.7 \mathrm{ij}$ & $1.4 \mathrm{n}$ \\
\hline \multicolumn{5}{|l|}{ C. aenigma } \\
\hline HBHP-4 & $16.5 \pm 1.3 \times 5.1 \pm 0.4$ & $12.2 \mathrm{ij}$ & $1.3 \mathrm{hij}$ & $1.6 \mathrm{mn}$ \\
\hline HBHР-5 & $15.8 \pm 1.5 \times 4.9 \pm 0.4$ & $13.1 \mathrm{c}$ & 1.4 hij & $1.5 \mathrm{mn}$ \\
\hline \multicolumn{5}{|c|}{ C. gloeosporioides } \\
\hline JXYX-34 & $16.8 \pm 2.0 \times 5.3 \pm 0.4$ & $12.1 \mathrm{j}$ & $1.0 \mathrm{ij}$ & $2.3 \mathrm{lmn}$ \\
\hline
\end{tabular}


including ITS, TUB2, ACT, CAL, HIS3, GS, SOD2, GAPDH, and CHSI, and a number of species have been segregated from this species complex (Weir et al. 2012). C. gloeosporioides sensu lato isolates from many host plants have been restudied to further investigate the taxonomy and phylogenetic relationships using phylogenetic analyses (De Silva et al. 2017; Han et al. 2016; Liu et al. 2013). In order to better understand the pathogen characterization, it is worth analyzing multiple traits of the Colletotrichum spp. of Ca. oleifera anthracnose in China using phylogenetic analyses.

In this study, a total of 232 isolates were obtained from the leaves and fruits of tea-oil tree in eight provinces, representing a broad geographic distribution of tea-oil tree plantations in China. All isolates were studied by morphological and cultural characterization, including colony characteristics, growth rates, and conidial and appressorium characteristics. Some differences in morphology and cultural characterization were observed among the isolates, but these isolates could not be differentiated within the $C$. gloeosporioides species complex based on the morphological and cultural differences. Thus, it was worth using multilocus phylogenetic analyses to segregate these taxa.

ITS, TUB2, ACT, CAL, GAPDH, and CHSI were employed in the phylogenetic analysis. Phylogenetic analysis showed that 232 Colletotrichum isolates associated with $\mathrm{Ca}$. oleifera anthracnose belong to five species: $C$. camelliae, $C$. fructicola, $C$. siamense, $C$. aenigma, and $C$. gloeosporioides s.s. This result differs from those reported previously on the causative agents of anthracnose on tea-oil trees. Previous studies have reported $C$. gloeosporioides as the causal agent, based on the morphology or sequences of only one locus (usually ITS) for identification (Cannon et al. 2012; Schoch et al. 2012; Zhu et al. 2015). In addition, this study is the first report to use multiple-locus sequences to analyze a large number of samples of the $C$. gloeosporioides species complex from the fruits of Ca. oleifera in China. Furthermore, this study reported C. camelliae, C. fructicola, C. siamense, and C. gloeosporioides s.s. from the leaves of Ca. oleifera, in agreement with Li et al. (2016).

According to current data in this study, $C$. camelliae was the predominant species associated with fruits of $C$ a. oleifera anthracnose in China, whereas $C$. fructicola was the predominant species associated with leaves. Although $C$. siamense, $C$. aenigma, and $C$. gloeosporioides s.s. are reported, they are not common on Ca. oleifera anthracnose; in this study, there were only five isolates of $C$. siamense in Guangxi and Guangdong, two isolates of C. aenigma in Hubei, and one isolate of $C$. gloeosporioides s.s. in Jiangxi. Li et al. (2016) researched the isolates from tea-oil tree leaves using the ITS, CAL, GS, and GAPDH genes or regions. Five species were reported, including C. fructicola, C. camelliae, C. siamense, C. gloeosporioides s.s., and an unclassified species, but $C$. aenigma was not reported. In addition, $C$. fructicola was the predominant species associated with leaves, in agreement with our study. However, isolates from fruits of $\mathrm{Ca}$. oleifera anthracnose were not studied by Li et al. (2016).

Virulence tests using five species of Colletotrichum isolates showed that all species were pathogenic to leaves and fruits of $C a$. oleifera, and $C$. camelliae species showed stronger virulence on both leaves and fruits, with lesion diameters ranging from 3.5 to $9.4 \mathrm{~mm}$ on leaves and from 2.4 to $12.8 \mathrm{~mm}$ on fruits. The virulence discrepancy of $C$. camelliae and $C$. fructicola could be attributable to the utilization of a single Ca. oleifera cultivar. Because different $\mathrm{Ca}$. oleifera cultivars may have different resistance to $C$. camelliae and $C$. fructicola, more cultivars of Ca. oleifera should be studied for the variation of their resistance to Colletotrichum pathogens in the future. Furthermore, symptoms may vary considerably with factors such as the varieties and conditions of the fruits, relative humidity and temperature, and the inoculum concentration (Freeman et al. 1996; Han et al. 2016). Hence, the results in this study may not reflect the full virulence potential. Additional research should be conducted to determine the virulence potential of Colletotrichum species under field conditions with natural inoculum rather than just in vitro artificial inoculation (Mo et al. 2018).
The Colletotrichum isolates from $\mathrm{Ca}$. oleifera examined in this study showed diversity based on sequence analysis and morphological characteristics. Higher genetic diversity is often correlated with higher evolutionary potential and with a greater ability to adapt to changing environmental conditions (McDonald and Linde 2002). In addition, the fungi of anthracnose in Ca. oleifera were reported to be highly resistant to carbendazim (Li et al. 2012). Future studies should focus on the epidemiology and fungicide sensitivity of the important plant fungal pathogen to develop effective management of Ca. oleifera anthracnose disease, on the pathogenic molecular mechanism, and on the interaction between the aggressive pathogens and $\mathrm{Ca}$. oleifera to develop effective resistant varieties.

\section{Literature Cited}

Altschul, S. F., Gish, W., Miller, W., Myers, E. W., and Lipman, D. J. 1990. Basic local alignment search tool. J. Mol. Biol. 215:403-410.

Cai, L., Hyde, K. D., Taylor, P. W. J., Weir, B. S., Waller, J. M., Abang, M. M. Zhang, J. Z. M., Yang, Y. L., Phoulivong, S., and Liu, Z. Y. 2009. A polyphasic approach for studying Colletotrichum. Fungal Divers. 39:183-204.

Cannon, P. F., Damm, U., Johnston, P. R., and Weir, B. S. 2012 Colletotrichum-Current status and future directions. Stud. Mycol. 73: 181-213.

Carbone, I., and Kohn, L. 1999. A method for designing primer sets for speciation studies in filamentous ascomycetes. Mycologia 91:553-556.

Damm, U., Woudenberg, J. H. C., Cannon, P. F., and Crous, P. W. 2009 Colletotrichum species with curved conidia from herbaceous hosts. Fungal Divers. 39:45-87.

De Silva, D. D., Ades, P. K., Crous, P. W., and Taylor, P. W. J. 2017 Colletotrichum species associated with chili anthracnose in Australia. Plan Pathol. 66:254-267.

Deng, X. L., and Xie, G. S. 2008. Development of refining squeezing tea oil Chem. Bioeng. 25:46-48.

Freeman, S., Katan, T., and Shabi, E. 1996. Characterization of Colletotrichum gloeosporioides isolates from avocado and almond fruits with molecular and pathogenicity tests. Appl. Environ. Microbiol. 62:1014-1020.

Freeman, S., Minz, D., Jurkevitch, E., Maymon, M., and Shabi, E. 2000. Molecular analyses of Colletotrichum species from almond and other fruits. Phytopathology 90:608-614.

Fu, M., Crous, P. W., Bai, Q., Zhang, P. F., Xiang, J., Guo, Y. S., Zhao, F. F., Yang, M. M., Hong, N., Xu, W. X., and Wang, G. P. 2019. Colletotrichum species associated with anthracnose of Pyrus spp. in China. Persoonia 42:1-35.

Glass, N. L., and Donaldson, G. C. 1995. Development of primer sets designed for use with the PCR to amplify conserved genes from filamentous ascomycetes. Appl. Environ. Microbiol. 61:1323-1330.

Han, Y. C., Zeng, X. G., Xiang, F. Y., Ren, L., Chen, F. Y., and Gu, Y. C. 2016. Distribution and characteristics of Colletotrichum spp. associated with anthracnose of strawberry in Hubei, China. Plant Dis. 100:996-1006.

Hyde, K. D., Cai, L., Cannon, P. F., Crouch, J. A., Crous, P. W., Damm, U., Goodwin, P. H., Chen, H., Johnston, P. R., Jones, E. B. G., Liu, Z. Y., Mckenzie, E. H. C., Moriwaki, J., Noireung, P., Pennycook, S. R., Pfenning, L. H., Prihastuti, H., Sato, T., Shivas, R. G., Tan, Y. P., Taylor, P. W. J., Weir, B. S., Yang, Y. L., and Zhang, J. Z. 2009. Colletotrichum-Names in current use. Fungal Divers. 39:147-182.

Jin, A. X., Zhou, G. Y., and Li, H. 2009. Progress, problem and prospect of oil camellia anthracnose (Colletotrichum gloeosporioides) research. For. Pest Dis. 28:27-30.

Larkin, M. A., Blackshields, G., Brown, N. P., Chenna, R., Mcgettigan, P. A., McWilliam, H., Valentin, F., Wallace, I. M., Wilm, A., Lopez, R., Thompson, J. D., Gibson, T. J., and Higgins, D. G. 2007. Clustal W and Clustal X version 2.0. Bioinformatics 23:2947-2948.

Li, H., Zhou, G. Y., Liu, J. Y., and Xu, J. P. 2016. Population genetic analyses of the fungal pathogen Colletotrichum fructicola on tea-oil trees in China. PLoS One 11:e0156841.

Li, H., Zhou, G. Y., Zhang, H. Y., Liu, J. A., and Peng, K. 2012. Resistance of Colletotrichum gloeosporioides to benzimidazole fungicide carbendazim in Camellia oleifera nurseries. Acta Phytopathologica Sin. 42:206-213.

Li, H., Zhu, X. D., Liu, J. A., and Xu, J. P. 2014. Population genetic structure of Colletotrichum gloeosporioides causing anthracnose of Camellia oleifera in China. Acta Phytopathologica Sin. 44:620-628.

Librado, P., and Rozas, J. 2009. DnaSP v5: A software for comprehensive analysis of DNA polymorphism data. Bioinformatics 25:1451-1452.

Liu, F., Damm, U., Cai, L., and Crous, P. W. 2013. Species of the Colletotrichum gloeosporioides complex associated with anthracnose disease of Proteaceae. Fungal Divers. 61:89-105.

Liu, J. A., He, L., and Zhou, G. Y. 2009. Specific and rapid detection of Camellia oleifera anthracnose pathogen by nested-PCR. Afr. J. Biotechnol. 8:1056-1061.

Lou, Y., Han, Y., Yang, L., Wu, M., Zhang, J., Cheng, J. S., Wang, M. Y., Jiang, D. H., Chen, W. D., and Li, G. Q. 2015. CmpacC regulates mycoparasitism, oxalate degradation and antifungal activity in the mycoparasitic fungus Coniothyrium minitans. Environ. Microbiol. 17:4711-4729. 
McDonald, B. A., and Linde, C. 2002. The population genetics of plant pathogens and breeding strategies for durable resistance. Euphytica 124:163-180.

Mo, J., Zhao, G., Li, Q., Soalngi, G. S., Tang, L., Guo, T. X., Huang, S. P., and Hsiang, T. 2018. Identification and characterization of Colletotrichum species associated with mango anthracnose in Guangxi, China. Plant Dis. 102: 1283-1289.

O'Donnell, K., and Cigelnik, E. 1997. Two divergent intragenomic rDNA ITS2 types within a monophyletic lineage of the fungus Fusarium are monorthologues. Mol. Phylogenet. Evol. 7:103-116.

Peakall, R., and Smouse, P. E. 2006. GENALEX 6: Genetic analysis in Excel. Population genetic software for teaching and research. Mol. Ecol. Notes 6: 288-295.

Peng, Y. L., and Shishiyama, J. 1988. Temporal sequence of cytological events in rice leaves infected with Pyricularia oryzae. Can. J. Bot. 66:730-735.

Penzig, A. G. O. 1882. Funghi agrumicoli: Contribuzione allo studio dei funghi parassiti degli agrumi. Michelia 2:385-508.

Photita, W., Taylor, P. W. J., Ford, R., Hyde, K. D., and Lumyong, S. 2005. Morphological and molecular characterization of Colletotrichum species from herbaceous plants in Thailand. Fungal Divers. 18:117-133.

Prihastuti, H., Cai, L., Chen, H., Mckenzie, E. H. C., and Hyde, K. D. 2009. Characterization of Colletotrichum species associated with coffee berries in northern Thailand. Fungal Divers. 39:89-109.

Sambrook, J., Frisch, E. F., and Maniatis, T. 1989. Molecular Cloning: A Laboratory Manual, 2nd ed. Cold Spring Harbor Laboratory, New York, NY.

Schoch, C. L., Seifert, K. A., Huhndorf, S., Robert, V., Spouge, J. L., Levesque, C. A., Chen, W.; Fungal Barcoding Consortium. 2012. Nuclear ribosomal internal transcribed spacer (ITS) region as a universal DNA barcode marker for fungi. Proc. Natl. Acad. Sci. U.S.A. 109:6241-6246.

State Administration of Forestry of China. 2016. Tea-Oil Camellia Cultivars in China. China Forestry Press, Beijing.

Sutton, B. C. 1980. Fungi imperfecti with pycnidia, acervuli and stromata. Pages 523-537 in: The Coelomycetes. C. M. I., Kew, UK.
Templeton, M. D., Rikkerink, E. H., Solon, S. L., and Crowhurst, R. N. 1992 Cloning and molecular characterization of the glyceraldehyde-3-phosphate dehydrogenase-encoding gene and cDNA from the plant pathogenic fungus Glomerella cingulata. Gene 122:225-230.

Valero, M., García-Martínez, S., Giner, M. J., Alonso, A., and Ruiz, J. J. 2010. Benomyl sensitivity assays and species-specific PCR reactions highlight association of two Colletotrichum gloeosporioides types and C. acutatum with rumple disease on Primofiori lemons. Eur. J. Plant Pathol. 127:399-405.

von Arx, J. A. 1957. Die Artender Gattung Colletotrichum Cda. Phytopathol. Z. 29:414-468.

Wang, W. J., Chen, C. G., and Cheng, J. 2007. The medicinal active role of tea oil in health care. Food Nutr. China 9:48-51.

Wang, Y. X., Chen, J. Y., Li, D. W., Zheng, L., and Huang, J. B. 2017. CglCUT1 gene required for cutinase activity and pathogenicity of Colletotrichum gloeosporioides causing anthracnose of Camellia oleifera. Eur. J. Plant Pathol. 147:103-114.

Weir, B. S., Johnston, P. R., and Damm, U. 2012. The Colletotrichum gloeosporioides species complex. Stud. Mycol. 73:115-180.

White, T. J., Bruns, T., Lee, S., and Taylor, J. 1990. Amplification and direct sequencing of fungal ribosomal RNA genes for phylogenetics. Pages 315-322 in: PCR Protocols: A Guide to Methods and Applications. M. Innis, D. Gelfand, J. Sninsky, and T. White, eds. Academic Press, San Diego, CA.

Wu, G. J. 1985. Economic Forest Pathology. China Forestry Press, Beijing.

Yang, Y. L., Liu, Z. Y., Cai, L., Hyde, K. D., Yu, Z. N., and McKenzie, E. H. C. 2009. Colletotrichum anthracnose of Amaryllidaceae. Fungal Divers. 32 229-253.

Zhou, G. Y., Song, G. T., and Li, H. 2007. Present situation and countermeasures to control Camellia oleifera pest and disease. J. Cent. S. Univ. For. Technol. 27: 179-182.

Zhu, Y. Z., Liao, W. J., Zou, D. X., Wu, Y. J., and Deng, Y. 2015. Identification and biological characteristics of the pathogen from Camellia oleifera anthracnose in Guangxi. J. Plant Prot. 42:382-389.

Zhuang, R. L. 2008. Teaoil Camellia of China. China Forestry Press, Beijing. 